\title{
Consideration of Diurnal Variations in Human Blood NAD and NADP Concentrations
}

\author{
Tsutomu FUKUWATARI and Katsumi SHIBATA \\ Department of Food Science and Nutrition, School of Human Cultures, The University of Shiga Prefecture, \\ 2500 Hassaka, Hikone, Shiga 522-8533, Japan
}

(Received October 1, 2008)

\begin{abstract}
Summary The sum of the urinary excretion of nicotinamide and its catabolites, which are metabolites of NAD and NADP, were observed to have clear diurnal variations in human urine. Then, we examined whether NAD and NADP in blood also showed the diurnal variation. All subjects were housed in the same facility and given the same diet during the experiment. In addition, we examined whether diurnal variations were affected by the intakes of dietary nicotinamide or not. As a result, neither the NAD nor the NADP content of the blood shows the diurnal variation regardless of the administered amount of nicotinamide. The concentrations of NAD and NADP did not increase according to the intake of nicotinamide. The existence of a mechanism by which NAD and the NADP levels of the blood are constantly maintained by the adjustment of the amount of excretion to the urinary bladder, was suggested.
\end{abstract}

Key Words diurnal variation, NAD, blood, human, vitamin

We reported a diurnal variation in the NAD and NADP catabolites $N^{1}$-methylnicotinamide, $N^{1}$-methyl2-pyridone-5-carboxamide, and $N^{1}$-methyl-4-pyridone3-carboxamide was observed (1) and an elevation of blood NAD level after moderate exercise (2). In the present study, we examined whether NAD and NADP in blood also showed the diurnal variation. In addition, we examined whether diurnal variations were affected by the intakes of dietary nicotinamide or not.

Ten healthy male Japanese college students participated in the present experiment. They did not have regular use of medications or dietary supplements, or habitual alcohol or cigarette consumption. Their age, body weight, height and body mass index (mean \pm SD) were $22.1 \pm 2.3 \mathrm{y}$ old, $63.6 \pm 5.2 \mathrm{~kg}, 174.0 \pm 4.6 \mathrm{~cm}$, and $21.0 \pm 1.6 \mathrm{~kg} / \mathrm{m}^{2}$, respectively. This study was reviewed and approved by The University of Shiga Prefecture.

All subjects $(n=10)$ were housed in the same facility and given the same diet. The experimental period was $4 \mathrm{wk}$. The diet consisted of bread, margarine, ham, yoghurt, tomato, lettuce, and milk as breakfast; rice, toasted and seasoned laver, luncheon meat, boiled egg, raw cabbage, miso-soup, and Japanese tea as lunch; rice, soy sauce-seasonal Pacific saury, tofu (soybean curd), spinach (leaves, boiled), kiwifruit and Japanese tea as dinner; and cheese and jelly fruit mix as a midnight snack. The nutrient elements are shown in Table 1. Nutrients were calculated by using Standard Tables of Food Composition in Japan, Fifth revised and enlarged edition (3).

E-mail; fukkie@shc.usp.ac.jp
The subjects took the diet on days 1 to 5 of each week (experimental period, $4 \mathrm{wk}$ ). But, they lived freely to soften the restraint on days 6 and 7 of each week. Approximately 1, 3- and 6-fold of the synthesized water-soluble vitamin mixture as vitamin mixture A, B and $C$ shown in Dietary Reference Intakes for Japanese, 2005, were made (Table 2). They were given the diet only for the 1st week, the diet with vitamin mixture A for the 2 nd week, the diet with vitamin mixture B for the 3rd week, and the diet with vitamin mixture $C$ for the 4 th week. One third of the dose was put into a small gelatinous capsule, and the capsule was administered three times daily after breakfast, lunch and dinner. A $10-\mu \mathrm{L}$ of finger blood was periodically taken at 08:00, 12:00, 18:00, and 21:00 an day 5 of each week and 32:00 which means 08:00 on day 6 . The blood $(10-\mu \mathrm{L})$ was immediately put into a micro tube containing 200$\mu \mathrm{L}$ of cold $50 \mathrm{~mm}$ potassium phosphate buffer ( $\mathrm{pH} 6.0$ ) containing $100 \mathrm{~mm}$ nicotinamide and the mixture was immersed in a hot water bath at $90^{\circ} \mathrm{C}$ for exactly $1.5 \mathrm{~min}$, cooled on ice, and then centrifuged using an Eppendorf $\left(15,000 \mathrm{rpm}, 10 \mathrm{~min}, 4^{\circ} \mathrm{C}\right)$. The supernatant was stored at $-20^{\circ} \mathrm{C}$ until needed. The treatment was done within $1 \mathrm{~h}$ after the blood collection. The NAD $\left(\mathrm{NAD}^{+}+\mathrm{NADH}\right)$ and $\mathrm{NADP}\left(\mathrm{NADP}^{+}+\mathrm{NADPH}\right)$ were measured by the methods of Shibata and Murata (4) and Shibata and Tanaka (5), respectively.

Diurnal variations in the blood NAD and NADP were determined by two-way repeated measures analysis of variance with Bonferroni's post hoc test for multiple comparisons. STATVIEW software (version 5.0; Abacus Concepts, Berkeley, CA) was used for all analysis.

Figure 1 shows the diurnal variations of blood NAD 
Table 1. The composition of the diet

\begin{tabular}{|c|c|}
\hline Energy and nutrients & Amount \\
\hline Energy (kcal) & 2,648 \\
\hline Protein $(\mathrm{g})$ & 97.5 \\
\hline Fat $(\mathrm{g})$ & 86.7 \\
\hline Carbohydrates $(\mathrm{g})$ & 361 \\
\hline \multicolumn{2}{|l|}{ Water-soluble vitamins ${ }^{1}$} \\
\hline Vitamin $\mathrm{B}_{1}$ (mg as thiamin) & 1.12 \\
\hline Vitamin $\mathrm{B}_{2}$ (mg as riboflavin) & 1.72 \\
\hline Vitamin $\mathrm{B}_{6}(\mathrm{mg}$ as pyridoxine $)$ & 1.12 \\
\hline Vitamin $\mathrm{B}_{12}$ ( $\mu \mathrm{g}$ as cyanocobalamin) & 13.3 \\
\hline Niacin equivalent ${ }^{2}(\mathrm{mg})$ & 28.8 \\
\hline Pantothenic acid (mg) & 6.75 \\
\hline Folates ( $\mu \mathrm{g}$ as pteroylmonoglutamic acid) & 367 \\
\hline $\operatorname{Biotin}(\mu \mathrm{g})$ & - \\
\hline Vitamin C (mg as L-ascorbic acid) & 125 \\
\hline \multicolumn{2}{|c|}{$\begin{array}{l}{ }^{1} \text { Nutrients are calculated by using the Standard Tables of } \\
\text { Food Composition in Japan ( } 3 \text { ). } \\
{ }^{2} \text { The niacin equivalent intake was calculated as follows: } \\
\text { the average tryptophan content in food protein is } 1.1 \% \\
\text { and } 1 / 60 \text { (on a weight basis) of tryptophan taken was } \\
\text { converted into niacin in the body. } \\
97.5 \times 1,000 \times(1.1 / 100) \times(1 / 60)=17.9 \mathrm{mg} \text {. } \\
17.9 \text { (biosynthesized from tryptophan) }+10.8 \text { (niacin } \\
\text { from food) }=28.8 \text {. }\end{array}$} \\
\hline
\end{tabular}

Table 2. The vitamin contents in the vitamin mixtures for 3 capsules per day.

\begin{tabular}{lrrr}
\hline & V. mix. A & V. mix. B & V. mix. C \\
\hline Thiamin & $1.4 \mathrm{mg} / \mathrm{d}$ & $4.2 \mathrm{mg} / \mathrm{d}$ & $8.4 \mathrm{mg} / \mathrm{d}$ \\
Riboflavin & $1.6 \mathrm{mg} / \mathrm{d}$ & $4.8 \mathrm{mg} / \mathrm{d}$ & $9.6 \mathrm{mg} / \mathrm{d}$ \\
Pyridoxine & $1.4 \mathrm{mg} / \mathrm{d}$ & $4.2 \mathrm{mg} / \mathrm{d}$ & $8.4 \mathrm{mg} / \mathrm{d}$ \\
Cyanocobalamin & $2.4 \mu \mathrm{g} / \mathrm{d}$ & $7.2 \mu \mathrm{g} / \mathrm{d}$ & $14.4 \mu \mathrm{g} / \mathrm{d}$ \\
Nicotinamide & $15 \mathrm{mg} / \mathrm{d}$ & $45 \mathrm{mg} / \mathrm{d}$ & $90 \mathrm{mg} / \mathrm{d}$ \\
Pantothenic acid & $6 \mathrm{mg} / \mathrm{d}$ & $18 \mathrm{mg} / \mathrm{d}$ & $36 \mathrm{mg} / \mathrm{d}$ \\
Pteroylmonoglutamic acid & $240 \mu \mathrm{g} / \mathrm{d}$ & $720 \mu \mathrm{g} / \mathrm{d}$ & $1,440 \mu \mathrm{g} / \mathrm{d}$ \\
Biotin & $50 \mu \mathrm{g} / \mathrm{d}$ & $150 \mu \mathrm{g} / \mathrm{d}$ & $300 \mu \mathrm{g} / \mathrm{d}$ \\
Ascorbic acid & $100 \mathrm{mg} / \mathrm{d}$ & $300 \mathrm{mg} / \mathrm{d}$ & $600 \mathrm{mg} / \mathrm{d}$ \\
\hline & \multicolumn{3}{c}{}
\end{tabular}

and NADP. Neither the NAD nor the NADP content of the blood shows the diurnal variation regardless of the administered amount of nicotinamide. The blood concentrations of NAD in the 1st, 2nd, 3rd, and 4th week were $29.9 \pm 4.2$ (mean \pm SD for 50 samples), $27.7 \pm 4.1$, $31.4 \pm 4.1$, and $30.0 \pm 4.9 \mathrm{nmol} / \mathrm{mL}$, respectively. The blood concentrations of NADP in the 1st, 2nd, 3rd, and 4 th week were $10.0 \pm 2.1$ (mean \pm SD for 50 samples), $9.6 \pm 1.4,10.3 \pm 1.7$, and $10.4 \pm 1.2 \mathrm{nmol} / \mathrm{mL}$, respectively. The concentrations of NAD and NADP did not increase according to the intake of nicotinamide and diurnal variations were not observed. So, we calculated the mean \pm SD by using whole values $(n=200)$. The blood NAD content was $29.7 \pm 4.6 \mathrm{nmol} / \mathrm{mL}$, and the blood NADP content was $10.1 \pm 1.6 \mathrm{nmol} / \mathrm{mL}$. These values were almost the same as reported previously (2). Recently, Creeke et al. (6) reported that blood NAD and NADP concentrations were not depressed in subjects
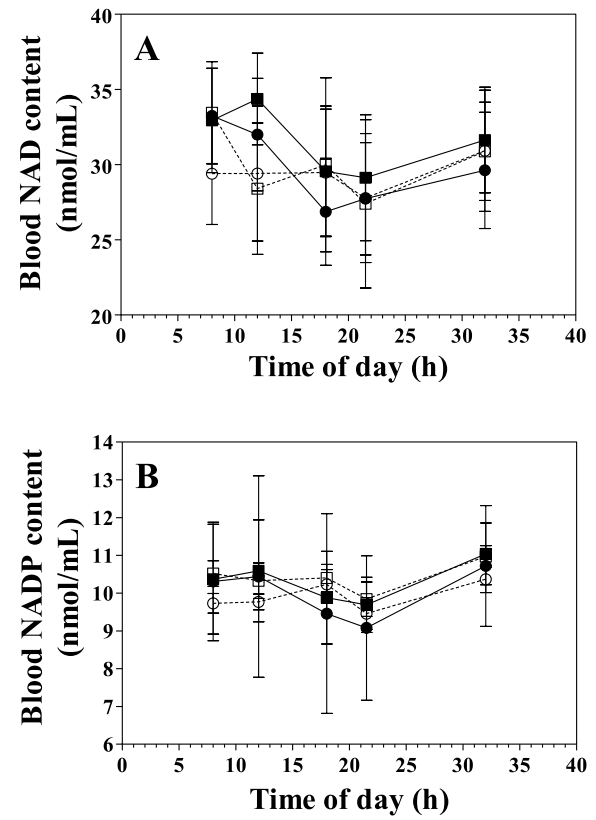

Fig. 1. The alterations in time of day of the blood NAD (A) and NADP (B) concentrations. •, 1st-week (basal diet); O, 2nd-week (basal diet+V. mix. A); $\mathbf{a , 3 r d - w e e k ~}$ (basal diet +V. mix. B); $\square$, 4th-week (basal diet +V. mix. C). Values are means \pm SD for 10 subjects.

with clinical pellagra. Their reported values in pellagrins were $29.7 \mathrm{nmol} / \mathrm{mL}$ in NAD, and $26.1 \mathrm{nmol} / \mathrm{mL}$ in NADP vs in healthy subjects $24.3 \mathrm{nmol} / \mathrm{mL}$ in NAD and $19.6 \mathrm{nmol} / \mathrm{mL}$ in NADP (6). They also reported that pellagrins were cured by administering $100 \mathrm{mg}$ of nicotinamide, but increases in the levels of NAD and NADP were not observed (6). On the other hand, Fukuwatari et al. (2) revealed that exercise affects the blood NAD and NADP levels in humans and mice. In that case, to deal with acute energy expenditure, the salvage pathway of NAD would be accelerated by decreasing the catabolism of NAD. Generally, the blood concentrations of NAD and NADP are regulated by the reaction of nicotinamide phosphoribosyltransferase which is inhibited by NAD (7). We think that this is the main reason why the blood concentrations of NAD and NADP did not increase even when the intake of nicotinamide increased. The existence of a mechanism where by NAD and NADP levels of the blood were maintained constantly without diurnal variation, by the adjustment of the amount of the urinary excretion, was suggested.

Erythrocyte produces ATP by glycolysis. The TCA cycle doesn't exist. Therefore, we think that maintaining the concentration of NAD is equivalent to maintaining the ATP production ability constantly. On the other hand, NADP is an end product of the antioxidation system of the erythrocyte membrane. Therefore, we think that it has the mechanism maintained constantly.

We permitted that the urinary excretion of nicotinamide and its catabolites was not permitted until the blood NAD was saturated, and that the urinary excretion of nicotinamide catabolites increased for the first time after the blood NAD was saturated (8). Furthermore, we reported that the blood NAD did not change, 
though the urinary excretion of nicotinamide and its catabolites decreased when rats were fasted (9). Therefore, urine is a better sample than blood in order to evaluate nutritional status.

\section{Acknowledgments}

This investigation is a part of results in "Studies on the requirement of water-soluble vitamins in Japanese (principal investigator, Katsumi Shibata)," which was supported by the Ministry of Health, Labor and Welfare.

\section{REFERENCES}

1) Okamoto H, Ishikawa A, Yoshitake Y, Kodama N, Nishimuta M, Fukuwatari T, Shibata K. 2003. Diurnal variations in human urinary excretion of nicotinamide catabolites: effects of stress on the metabolism of nicotinamide. Am J Clin Nutr 77: 406-410.

2) Fukuwatari T, Shibata K, Ishihara K, Fushiki T, Sugimoto E. 2001. Elevation of blood NAD level after moderate exercise in young women and mice. J Nutr Sci Vitaminol 47: 177-179.

3) Resources Council, Science and Technology Agency. 2004. Standard Tables of Food Composition in Japan, Fifth revised and enlarged edition, 2004. Tokyo. (in Jap- anese).

4) Shibata K, Murata K. 1986. Blood NAD as an index of niacin nutrition. Nutr Int 2: 177-181.

5) Shibata K, Tanaka K. 1986. Simple measurement of blood NADP and blood levels of NAD and NADP in humans. Agric Biol Chem 50: 2941-2942.

6) Creeke PI, Dibari F, Cheung E, van den Briel T, Kyroussis E, Seal AJ. 2007. Whole blood NAD and NADP concentrations are not depressed in subjects with clinical pellagra. J Nutr 137: 2013-2017.

7) Shibata K, Taguchi H, Nishitani Y, Okumura K, Shimabayashi Y, Matsushita N, Yamazaki H. 1989. End product inhibition of the activity of nicotinamide phosphoribosyltransferase from various tissues of rats by NAD. Agric Biol Chem 53: 2283-2284.

8) Shibata K, Matsuo H. 1989. Effect of gradually increasing levels of nicotinamide in a niacin-free and tryptophan-limited diet on the blood NAD levels and the urinary excretion of nicotinamide metabolites in rats. Agric Biol Chem 53: 1333-1336

9) Shibata K, Iwai K. 1988. Effects of fasting on the blood NAD level, and urinary excretion of 5-hydroxyindole-3acetic acid, and nicotinamide and its metabolites in rats. Agric Biol Chem 52: 2287-2292. 